\title{
Customer satisfaction measurement using fuzzy neural network
}

\author{
Ayad Hendalianpour* and Jafar Razmi
}

School of Industrial Engineering, College of Eng, Tehran University, Tehran, Iran

\begin{tabular}{l}
\hline C H R O N I C L E \\
\hline Article history: \\
Received February 25, 2016 \\
Received in revised format: \\
March 28, 2016 \\
Accepted August 28, 2016 \\
Available online \\
August 302016 \\
\hline Keywords: \\
Customer satisfaction \\
measurement \\
Fuzzy neural network \\
Linguistic variable \\
Fuzzy inference system
\end{tabular}

\section{A B S T R A C T}

Investigating the Customer Satisfaction Measurement (CSM) plays an important role in determining the range of customer needs and expectations resulting from delivered products or received services. In this research, a novel approach is proposed for measuring the customer's satisfaction measurement. Due to ambiguity and lack of information related to evaluation criteria, in the proposed model, the customer feedbacks are considered as linguistic terms and due to the dominance of non -linear relations on behaviors and judgments of human, the result is obtained using a Fuzzy Neural Network. In continuation, roles of the fuzzy inference system for customer's satisfaction are defined and determined for different conditions of customer's judgments. Applicability of the proposed model has been successfully implemented through a case study for investigating the customer's satisfaction on the basis of both qualitative and quantitative inputs.

(c) 2017 Growing Science Ltd. All rights reserved.

\section{Introduction}

Customer satisfaction is tied directly to profitability (Austen et al., 2012). If the customers are happy, they tend to become loyal (Bayraktar et al., 2012) and once they become loyal they not only buy more, but also recommend to other customers through word of mouth advertisement. Well-established research by Bain \& Company reports that, for many companies, an increase of 5\% in customer retention can increase profits by $25 \%$ to $95 \%$ (Pan et al., 2012). The same study reports it costs six to seven times more to gain a new customer than to keep an existing one (Li, 2011). Nowadays, businesses realize that one of the key success in the competitive marketplace is effective customer management. Companies see customer satisfaction as a strategic advantage and have invested significant amount of efforts in making sure that Customer Satisfaction Measurement (CSM) is high on the priority list. However, few companies have invested any effort in terms of having a continuous measurement strategy that can

* Corresponding author. Tel.: +989173396702

E-mail address: hendalianpour@ut.ac.ir (A. Hendalianpour)

(C) 2017 Growing Science Ltd. All rights reserved. doi: $10.5267 /$ j.ds1.2016.8.006 
signal potential dips in real-time (Li, 2011). With the recent growth of Do-It-Yourself study projects based on online surveys, performing customer satisfaction surveys has become more of an in-house operation. Many organizations look to improve when they are not effectively measure customer satisfaction. When a customer satisfaction program is effective and accepted, it should be more than just one survey that is sent out to all customers periodically. It needs to be an ongoing strategy of continuous measurement and improvement according to the feedback received. Validation of the improvements can be computed directly in terms of satisfaction indices (Chou et al., 2011).

The organization of the remainder is as follows: section 2 is a literature review. Section 3 , describes the linguistic variables. In Section 4 we briefly introduce the concepts of fuzzy number and relevant calculation procedure. In Section 5, we present fuzzy inference model's structure with fuzzy neural network considerations. In section 6 we present how to use a novel model for measuring the customer's satisfaction and a case study. At the end, conclusion remark is given in section 7.

\section{Literature review}

In the competitive markets, preservation and development of customers; causes an organization to be survived and consequently its profitability can be increased. Information associated with range of customer's satisfied degree and also the improvement and development of organization's processes is required, through investigating customer's satisfaction. During the past few years, most organizations have produced high quality products through relying on customer's comments and their valuable feedbacks (Choi et al., 2004), so that productions rate, sale and profitability of economic agencies represent a direct relationship with customer satisfaction (Saeidi et al., 2015). The higher satisfaction degree of products by the customer, may normally guarantee a higher products sale (Zeinalizadeh et al., 2015).

During the recent years, several models have been represented for measuring customer satisfaction on the basis of their judgments about evaluation indexes through quantitative or qualitative data. In the previous studies, researches have tried to model customer satisfaction approaches mostly using statistical calculations such as: regression, fuzzy regression, and neural network, etc. (Hussain et al., 2015). In this respect, He et al. (2015), Kuo et al. (2015) have designed some models in this area. Customer satisfaction can be defined as the psychological decision made on the basis of a specific service encounter when customers and service providers contact each other (Lin, 2007). Aleem et al. (2016) showed the interrelationships between quality service level (QSL) constructs and measured the chain effects on the digital content industry. Subsequent studies on customer satisfaction also demonstrated that product/service attributes influence overall satisfaction in non-linear and a symmetric manners (Albayrak \& Caber, 2016). In the study, carried out by Nagamachi (2016), the concept of significance of customer participation and comments made on designing a product is developed. In other study, he also expressed a model for interpreting emotions and excitements of customer in feature for designing products and its effect on customer's satisfaction. Another study, similar to Nagamachie's (2016) was performed with a different viewpoint; such as work performed by Han et al. (2000). They defined a new concept for developing traditional methods of designing products through emphasizing on efficiency and customers satisfaction.

In Park (2004) and Han's et al. (2000) model, the customer' judgments are received through quantitative data and fuzzy clustering of input data; then a multi-variable linear regression model was implemented for each cluster. For input data set; first, the membership function associated with each cluster was determined and then, the satisfaction amount was calculated on the basis of the output weight mean of regression equations. The fuzzy inference system of customer satisfaction was also represented through receiving quantitative input amounts for linguistic variables; on the adaptive network according to the fuzzy control system, Takagi -Sugeno - King (TSK), applied by Zarandi and Turksen (2004). The roles used for inference system was based on the multi - variable linear regression (MVLR) whose 
parameters were determined by the genetic algorithm (GA). The non-linear relationships among variables for calculating the satisfaction amount were considered in the work developed by Itagaki et al. (1994) which incorporates fuzzy inference system on the basis of learning rules. In this method, the error function of learning algorithm is defined on quantitative input data. Representing a model for measuring the customer's satisfaction was performed based on quantitative input data proposed by Grigoroudis and Siskos (2002). In their multi-criteria satisfaction analysis (MUSA), the quantitative amounts of input data, which includes customers judgment associated with evaluation indexes, were calculated using arrangement of a linear regression model. Calculating the quantitative amounts of qualitative inputs, apart from customer's judgment based approach, was performed due to some parameters such as number of customers, number of variables, and number of satisfaction levels.

Through reviewing the literature of customer satisfaction measurement models, a lack for a model with an ability for receiving and analysis the customer's judgments through qualitative statements and also considers non-linear relations in expressed comments, is clearly found. In this study, despite calculating the customers satisfaction amount through using fuzzy neural network (CSM\&FNN), inference system is also determined for different conditions of customers judgments.

\section{Linguistic Variables}

Linguistic variables refer to variables, the accepted values for which, consist of words and sentences from human or machine languages, instead of numbers (Zadeh, 2011). Linguistic variables (oral or non-numerical) are used in fuzzy logic, in the same way that numerical variables are used in mathematical calculations. Linguistic variables are described according to linguistic (oral) values which fall within a certain term set (words, expressions). Linguistic terms are qualities for linguistic variables. For instance, the linguistic variable "age," depending on subjective divisions and certain circumstances, could have a set of terms such as "young", "middle-aged" and "old". The fuzzy term set for "age"= \{"young", "not young", "not so young", "very young",..., "middle-aged", "not so middle-aged", ..., "old", "very old", "more or less old", ..., "not so young and not so old", "not young and not old" $\}$ Or, in another example, (blood) pressure could be considered as a linguistic variable able to contain such values (qualities) as low, high, very low, medium and very high. In mathematical language, we have: $(\mathrm{T}=$ Terms $)$, (Pressure $)=\{$ low, high, very low, medium, very high $\}$.

\section{A review on fuzzy numbers}

\subsection{Fuzzy numbers}

A fuzzy number is normalized and convex set in which there is, at least, one amount of equal membership grade. The fuzzy numbers can have very various shapes such as: Triangular, Trapezoidal, Bell-shaped and etc., where each one is identified with the membership grade function.

\subsection{Operations related to the fuzzy numbers}

On the basis of the development principles of fuzzy numbers represented by Zadeh (2011), the membership function and its behavior obtained from adding and multiplying the fuzzy numbers (figures) and also the algebraic function are defined through the followings:

$$
\begin{aligned}
& \mu_{A+B}(z)=\max \left\{\mu_{A}(x) \wedge \mu_{B}(y) \mid z=x+y\right\} \\
& \mu_{A B}(z)=\max \left\{\mu_{A}(x) \wedge \mu_{B}(y) \mid z=x y\right\} \\
& \mu_{f(N e t)}(z)=\max \left\{\mu_{N e t}(x) \mid z=f(x)\right\}
\end{aligned}
$$


where $A, B$ and Net are fuzzy numbers and, $\mu_{*}(\cdot)$ is the membership grade function of each fuzzy number and ${ }^{\wedge}$ is optimal operations.

\section{3. $\alpha$-Cuts}

The $\alpha$-cut of the fuzzy number $x$ is defined through the following:

$$
[X]_{\alpha}=\left\{x \mid \mu_{x}(x) \geq \alpha, x \in R\right\}, 0 \leq h \leq 1 .
$$

The amount of $\alpha$-cut of the fuzzy is a set of real numbers and in a close interval which can be displayed as the following,

$$
[X]_{\alpha}=\left[[X]_{\alpha}^{l},[X]_{\alpha}^{u}\right]
$$

where $[X]_{\alpha}^{l}$ and $[X]_{\alpha}^{u}$ are the low and high limits; obtained from $\alpha$-cut according to Fig. 1.

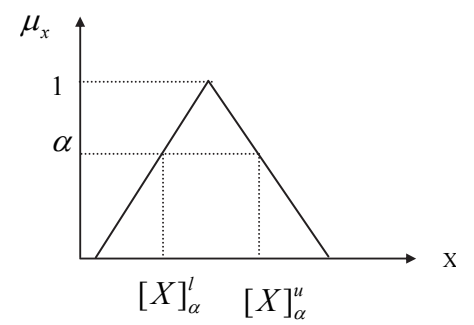

Fig. 1. $\alpha$-cut of fuzzy number

\subsection{Fuzzy number's operations in $\alpha$-cut}

If the defined arithmetic for intervals considered for further calculations, the operations such as adding and multiplying of fuzzy numbers and also the algebraic function of a fuzzy number are shown through the followings (Han et al., 2000):

$$
\begin{aligned}
& {[A]_{\alpha}+[B]_{\alpha}=\left[[A]_{\alpha}^{l},[A]_{\alpha}^{u}\right]+\left[[B]_{\alpha}^{l},[B]_{\alpha}^{u}\right]=\left[[A]_{\alpha}^{l}+[B]_{\alpha}^{l},[A]_{\alpha}^{u}+[B]_{\alpha}^{u}\right]} \\
& {[A]_{\alpha} \cdot[B]_{\alpha}=\left[[A]_{\alpha}^{l},[A]_{\alpha}^{u}\right] \cdot\left[[B]_{\alpha}^{l},[B]_{\alpha}^{u}\right]=\left[\min \left\{[A]_{\alpha}^{l} \cdot[B]_{\alpha}^{l},[A]_{\alpha}^{l} \cdot[B]_{\alpha}^{u},[A]_{\alpha}^{u} \cdot[B]_{\alpha}^{l},[A]_{\alpha}^{u} \cdot[B]_{\alpha}^{u}\right\},\right.} \\
& \left.\max \left\{[A]_{\alpha}^{l} \cdot[B]_{\alpha}^{l},[A]_{\alpha}^{l} \cdot[B]_{\alpha}^{u},[A]_{\alpha}^{u} \cdot[B]_{\alpha}^{l},[A]_{\alpha}^{u} \cdot[\mathbf{B}]_{\alpha}^{u}\right\}\right]=\left[[A]_{\alpha}^{l} \cdot[B]_{\alpha}^{l},[A]_{\alpha}^{u} \cdot[B]_{\alpha}^{u}\right] \text { for }, B \geq 0 \\
& f\left([N e t]_{\alpha}=f\left([N e t]_{\alpha}^{l},[N e t]_{\alpha}^{u}\right)=\left[f\left([N e t]_{\alpha}^{l}\right), f\left([N e t]_{\alpha}^{u}\right)\right.\right.
\end{aligned}
$$

\section{Customer satisfaction measurement}

In this section, we present a framework of a novel model which is expressed for measuring customer satisfaction. The question raised here is to learn how to calculate the whole satisfaction amount according to qualitative amounts of inputs and non -liner effects of expert judgment using a fine tuned fuzzy neural network.

\subsection{The structure of the customer satisfaction measurement model}

The customer satisfaction investigation is a multi-variables problem in which the total solution related to the satisfaction degree of customers is obtained according to their comments and feedbacks made on the evaluation criteria. In the represented model, the fuzzy inference system has been used according to Fig. 2 for calculating the overall satisfaction degree, so that it's input data are the qualitative statements obtained from customer's comments and the amount of the overall satisfaction, as an output, 
is obtained from the inference rules. In this knowledge based system, the inference rules are defined for different combinations of inputs and on the other hand the fuzzy neural network has been used in order to consider the non-linear relations dominant on expert judgments. The latter will cause to calculate the outputs of rules. Determination of membership functions for qualitative input statements and also making the result of rules be non-fuzzy have been represented respectively.

X: Linguistic Variable

Y: Output of Fuzzy number(s)

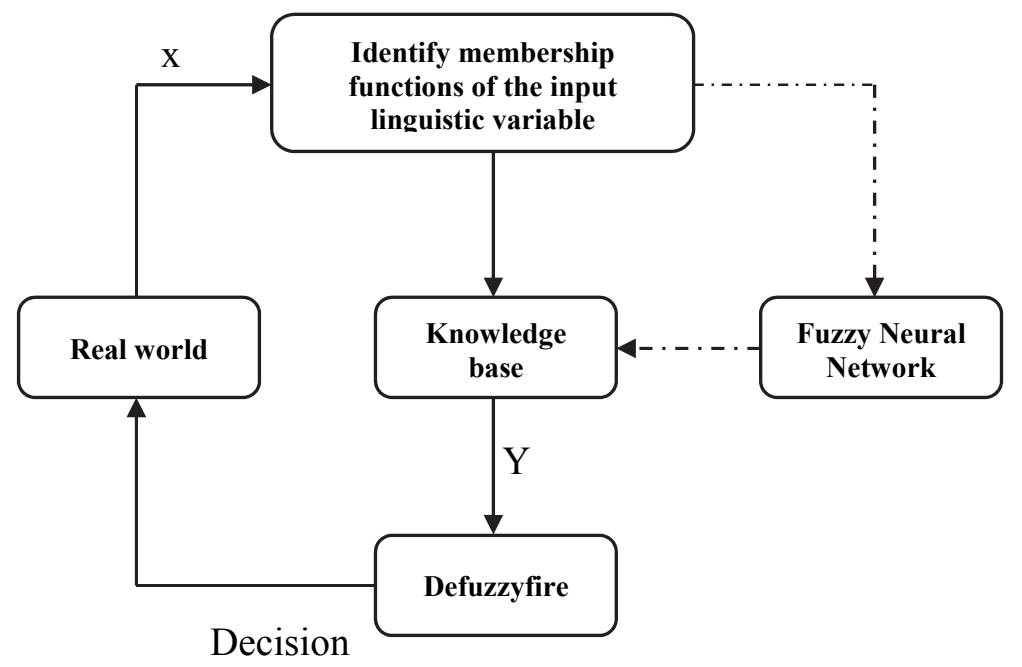

Fig. 2. The structure of fuzzy inference system for measuring customer satisfaction

\subsection{The membership functions of the linguistic variables}

The customers' judgment about evaluation criteria are always along with ambiguity and lack of certainty. They are taken from experts thought the comments made by customers, which is more convenient and suitable than numerical calculations. For "satisfaction" term as a linguistic variable, we can consider qualitative statement such as (low, relatively low, medium, high and relative high), etc., where each one shows a difference level of satisfaction. In the calculation procedure of satisfaction, changing the input qualitative statement to numerical amounts is then required. Through considering the lack of certainty, the qualitative statement of satisfaction can be shown through fuzzy numbers which include a set of numbers with different membership functions instead of definite number. For determining the membership grade function of fuzzy numbers, the professional person's comments are therefore used. The shape of the membership function can be different on the basis of the measurement problem and kind of satisfaction or different comments of the professionals. In Fig. 3, a sample of fuzzy numbers of satisfaction statements has been shown.

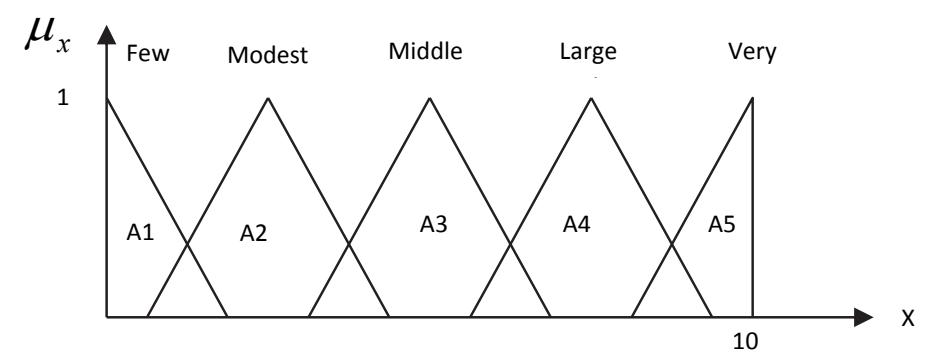

Fig. 3. The fuzzy numbers of satisfaction with triangular membership function 


\subsection{The fuzzy inference rules}

In the fuzzy inference system of the customer satisfaction measurement model, the system's knowledge is obtained according to "If-Then" rules. The input of rules includes different combinations of customer's judgments through qualitative statements and its conclusion is the expression for overall satisfaction degree through fuzzy numbers. The structure of rules, applied in this research, is as given as followings:

$$
R_{j} \text { : IF } x_{1} \text { is } A_{k_{1}}^{1}, \ldots, x_{i} \text { is } A_{k_{i}}^{i}, \ldots, x_{n} \text { is } A_{k_{n}}^{n} \text { Then } O_{j} \text { is } B_{j}
$$

where:

$X_{i}$ : The score of criteria $i,(i=1,2, \ldots, n)$

$A_{k_{i}}^{i}: k_{i}$ is the satisfaction level of the attribute related to variable $X_{i}$

$k_{i}$ : Number of the satisfaction levels of variable $X_{i}$

$R_{j}$ : The knowledge base rule of the fuzzy inference system $\mathrm{j}=1,2, \ldots, \mathrm{k}$

$\mathrm{K}$ : number of knowledge base rules and $K=k_{1} \times k_{2} \times \ldots \times k_{n} \quad\left(I f k_{1}=k_{2}=\ldots=k_{n}\right.$ ThenK $\left.=k^{n}\right)$

$O_{j}:$ The result of $\mathrm{jth}$ rules

$B_{j}$ : The fuzzy number related to the amount of satisfaction obtained from $\mathrm{jth}$ rule

In order to calculate the results of rules via fuzzy neural network, the amount of customer's satisfaction $(p=1,2, \ldots, m)$ related to evaluation indexes and also the overall score is obtained considering a vector $\left(X_{p 1}, X_{p 2}, \ldots, X_{p n}, T_{p}\right)$ as the target amount. Then, the $O_{p}$ which is the output amount of network is calculated for each customer and then the network's parameters are adjusted by using the learning algorithm of fuzzy neural network in order to decrease the error between $O_{p}$ and $T_{p}$. By using the final fuzzy neural network, the result amount of all the fuzzy inference system's knowledge base rules can be finally calculated.

\subsection{Satisfaction measurement using by fuzzy neural network}

Neural networks consist of a series of simple processors which are called "Unit" and they communicate with each other by communicative canals under "connection" title. The output of each unit is obtained through considering different weights and Bias within in unit. The neural networks adjust the weight amounts of connections and Bias ranges of each unit in different levels of the network through applying a learning structure by using train data, so that a significant accuracy is obtained for the approximate of the network's output amount. In neural networks, the output of network is affected by the amounts of connection's weight, unit's Bias and also input data of network. In the fuzzy inference system, obtaining the result is possible through fuzzy number via using neural networks and receiving input amounts or parameters of network through fuzzy numbers or combining fuzzy and certain numbers. In accomplished researches, in order to expand fuzzy inference capabilities by using neural networks, some models been represented for input and output data through fuzzy condition and certain amounts for network's parameters, fuzzy input and output and fuzzy parameters through triangular numbers (Ishibuchi et al., 1995), input and output data and also parameters through fuzzy numbers with different membership grade functions (Zimmermann, 1996). In the represented measurement model, the Ishibuchi et al., (1995) fuzzy neural network has been used in order to determine the result of inference rules which are according to a feed forward neural network with three input vector, hidden and output layers. The fuzzy parameters of the network follow a triangular shape, the inputs of network are 
estimated through fuzzy numbers with a membership grade function and the output of the network is obtained through fuzzy numbers.

\subsubsection{Calculating the output of fuzzy neural network}

The architecture of the fuzzy neural network has been shown in Fig. 4 for calculating the customer satisfaction amount.

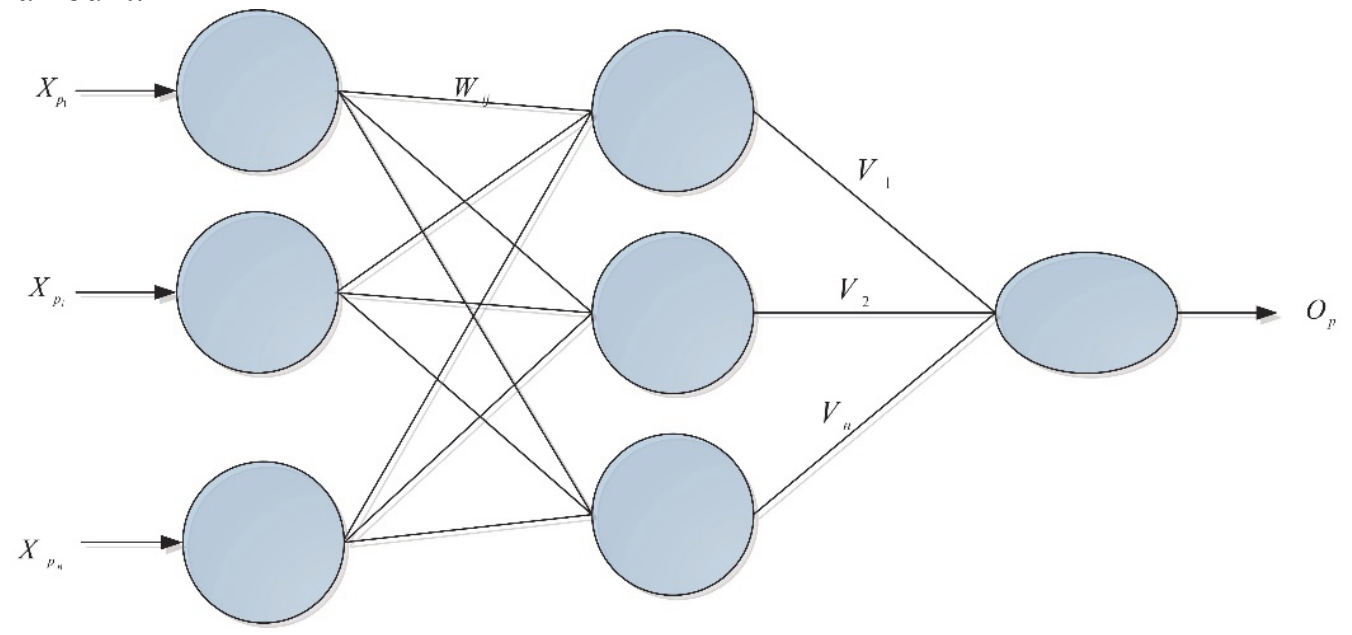

Fig. 4. Architecture of the proposed fuzzy neural network

The input and output relations of fuzzy neural network's units of above figure are as the followings:

- Inputs units:

$$
O_{p i}=X_{p i}, i=1,2, \ldots, n
$$

- Hidden units:

$$
\begin{aligned}
& O_{p j}=f\left(N e t_{p j}\right),(j=1,2, \ldots, m) \\
& N e t_{p j}=\sum_{i=1}^{n} W_{i j} \cdot O_{p i}+B_{j}
\end{aligned}
$$

- Output units:

$$
\begin{aligned}
& O_{p}=f\left(\mathrm{Net}_{p}\right) \\
& N e t_{p}=\sum_{j=1}^{m} V_{j} \cdot O_{p j}+B
\end{aligned}
$$

where $P$ is the number of input vectors, $X_{p i} i$ is the input vector variable of $\mathrm{p}, W_{i j}$ and $V_{j}$ are the weight of connections, $B_{j}$ and $B$ are the Bias amount of units and $O_{p}$ is the amount of network's output and it is equivalent to the whole satisfaction of customer for the product or received service in the customer satisfaction measurement model. The $f(x)=1 /(1+\exp (-x))$ is as the activation function of the neural network.

On the basis of the definition of h-level cut of fuzzy numbers, the input and output relations of neural network's units are as the followings with the fuzzy parameters and inputs: 
- Inputs units:

$$
\left[O_{p i}\right]_{h}=\left[X_{p i}\right]_{h}
$$

- Hidden units:

$$
\left[O_{p j}\right]=f\left(\left[\mathrm{Net}_{p j}\right]_{h}\right.
$$

$\left[N e t_{p j}\right]_{h}=\sum_{i=1}^{n}\left[W_{i j}\right]_{h} \cdot\left[O_{p i}\right]_{h}+\left[B_{j}\right]_{h}$

- Output units:

$$
\begin{aligned}
& {\left[O_{p}\right]=f\left(\left[N e t_{p}\right]_{h}\right.} \\
& {\left[N e t_{p}\right]_{h}=\sum_{j=1}^{m}\left[V_{j}\right]_{h} \cdot\left[O_{p j}\right]_{h}+[B]_{h}}
\end{aligned}
$$

Through using the defined arithmetic on the intervals 6,7 and 8 , by supposing positive input data, the input and output relations of units in the fuzzy neural network are written as the followings:

- Inputs units:

$$
\left[O_{p i}\right]_{h}=\left[\left[O_{p i}\right]_{h}^{l},\left[O_{p i}\right]_{h}^{u}\right]=\left[\left[X_{p i}\right]_{h}^{l},\left[X_{p i}\right]_{h}^{u}\right]
$$

- Hidden units:

$$
\begin{aligned}
& {\left[O_{p j}\right]_{h}=\left[\left[O_{p j}\right]_{h}^{l},\left[O_{p j}\right]_{h}^{u}\right]=\left[f\left[N e t_{p j}\right]_{h}^{l}, f\left[N e t_{p j}\right]_{h}^{u}\right]} \\
& {\left[N e t_{p j}\right]_{h}^{l}=\sum_{i=1}^{n}\left[W_{i l}\right]_{h}^{l} \cdot\left[O_{p i}\right]_{h}^{l}+\sum_{i=1}^{n}\left[W_{i l}\right]_{h}^{l} \cdot\left[O_{p i}\right]_{h}^{u}+\left[B_{j}\right]_{h}^{l}} \\
& {\left[W_{i j}\right]_{h}^{l} \geq 0 \quad\left[W_{i j}\right]_{h}^{l} \leq 0} \\
& {\left[N e t_{p j}\right]_{h}^{u}=\sum_{i=1}^{n}\left[W_{i l}\right]_{h}^{u} \cdot\left[O_{p i}\right]_{h}^{u}+\sum_{i=1}^{n}\left[W_{i l}\right]_{h}^{u} \cdot\left[O_{p i}\right]_{h}^{l}+\left[B_{j}\right]_{h}^{u}} \\
& {\left[W_{i j}\right]_{h}^{u} \geq 0 \quad\left[W_{i j}\right]_{h}^{u} \leq 0}
\end{aligned}
$$

- Output units:

$$
\begin{aligned}
& {\left[O_{p}\right]_{h}=\left[\left[O_{p}\right]_{h}^{l},\left[O_{p}\right]_{h}^{u}\right]=\left[f\left[\mathrm{Net}_{p}\right]_{h}^{l}, f\left[\mathrm{Net}_{p}\right]_{h}^{u}\right]} \\
& {\left[N e t_{p}\right]_{h}^{l}=\sum_{j=1}^{m}\left[V_{j}\right]_{h}^{l} \cdot\left[O_{p j}\right]_{h}^{l}+\sum_{j=1}^{m}\left[V_{j}\right]_{h}^{l} \cdot\left[O_{p}\right]_{h}^{u}+[B]_{h}^{l}} \\
& {\left[V_{j}\right]_{h}^{l} \geq 0 \quad\left[V_{j}\right]_{h}^{l} \leq 0} \\
& {\left[N e t_{p}\right]_{h}^{u}=\sum_{j=1}^{m}\left[V_{j}\right]_{h}^{u} \cdot\left[O_{p j}\right]_{h}^{u}+\sum_{j=1}^{m}\left[V_{j}\right]_{h}^{u} \cdot\left[O_{p}\right]_{h}^{l}+[B]_{h}^{u}} \\
& {\left[V_{j}\right]_{h}^{u} \geq 0 \quad\left[V_{j}\right]_{h}^{u} \leq 0}
\end{aligned}
$$

On the basis of the above mentioned formulas, through $\mathrm{h}$ variation in a $[0,1]$ interval, the membership grade function of the fuzzy number of the network's output is then calculated. 


\subsubsection{Learning rules in the fuzzy neural network}

If $T_{p}$ is the target amount and $O_{p}$ is the output amount of the neural network and it is analogous with the input vector $X_{p}=\left(X_{p 1}, X_{p 2}, \ldots, X_{p n}\right)$ the error amount of the neural network's operation is calculated through defining the cost function. In the fuzzy neural model used in Ishibuchi et al. (1996), the cost function in the h-level cut is defined through the following:

$$
\begin{aligned}
e_{p h} & =e_{p h}^{l}+e_{p h}^{u} \\
e_{p h}^{l} & =h \cdot \frac{\left(\left[T_{p}\right]_{h}^{l}-\left[O_{p}\right]_{h}^{l}\right)^{2}}{2} \\
e_{p h}^{u} & =h \cdot \frac{\left(\left[T_{p}\right]_{h}^{u}-\left[O_{p}\right]_{h}^{u}\right)^{2}}{2}
\end{aligned}
$$

The amount of $e_{p h}^{l}$ and $e_{p h}^{u}$ are in the cut-level h from squares of high-limit error and low-limit error respectively which have been weighted with coefficients $\frac{h}{2}$. Alteration of "h" amounts in interval $[0,1]$ of the cost function amount for the input vector $\mathrm{p}$ is:

$$
e_{p}=\sum_{h} e_{p h}
$$

In the learning process, the first amounts of the network's parameters are reformed by using a cost function in the way that their triangular structure is kept and the amounts of beginning, ending and width of the triangular fuzzy number change through decreasing the output error of the network. The triangular fuzzy numbers of network's weights and Bias are shown as the following:

$$
\begin{array}{ll}
W_{i j}=\left(W_{i j}^{l}, W_{i j}^{c}, W_{i j}^{u}\right) & V_{j}=\left(V_{j}^{l}, V_{j}^{c}, V_{j}^{u}\right) \\
B_{j}=\left(B_{j}^{l}, B_{j}^{c}, B_{j}^{u}\right) & B=\left(B^{l}, B^{c}, B^{u}\right)
\end{array}
$$

Alphabets L, C and V show low, central and above limits of triangular fuzzy numbers respectively. Through supposing the symmetry of fuzzy numbers, their centers are determined as the followings:

$$
\begin{array}{cc}
W_{i j}^{c}=\frac{W_{i j}^{l}+W_{i j}^{u}}{2} & V_{j}^{c}=\frac{V_{j}^{l}+V_{j}^{u}}{2} \\
B_{j}^{c}=\frac{B_{j}^{l}+B_{j}^{u}}{2} & B=\frac{B^{l}+B^{u}}{2}
\end{array}
$$

On the basis of the cost function $e_{p h}$, the modified amount of each parameters of the network is calculated as the sample $V_{j}$ :

$$
\begin{aligned}
& \Delta V_{j}^{l}(t)=-\eta \cdot \frac{\partial e_{p h}}{\partial V_{j}^{l}}+\alpha \cdot \Delta V_{j}^{l}(t-1) \\
& \Delta V_{j}^{u}(t)=-\eta \cdot \frac{\partial e_{p h}}{\partial V_{j}^{u}}+\alpha \cdot \Delta V_{j}^{u}(t-1)
\end{aligned}
$$

In which $\eta$ is a learning constant, $\alpha$ is the movement amount constant and $\mathrm{t}$ is the modification number. Due to the supposition of the triangular fuzzy symmetry, the center's amount of the network's 
parameters is obtained by using Eq. (22). The high and low limits of interval resolved by h-level cut are written as the followings:

$$
\begin{aligned}
& {\left[V_{j}\right]_{h}=\left[\left[V_{j}\right]_{h}^{l},\left[V_{j}\right]_{h}^{u}\right]} \\
& {\left[V_{j}\right]_{h}^{l}=V_{j}^{l}\left(1-\frac{h}{2}\right)+V_{j}^{u} \cdot \frac{h}{2}} \\
& {\left[V_{j}\right]_{h}^{u}=V_{j}^{l} \cdot \frac{h}{2}+V_{j}^{u}\left(1-\frac{h}{2}\right)}
\end{aligned}
$$

The derivatives of Eq. (23) can be written through the following format:

$$
\begin{aligned}
& \frac{\partial e_{p h}}{\partial V_{j}^{l}}=\frac{1}{2} \cdot \frac{\partial e_{p h}}{\partial\left[V_{j}\right]_{h}^{l}} \cdot \frac{\partial\left[V_{j}\right]_{h}^{l}}{\partial V_{j}^{l}}+\frac{1}{2} \cdot \frac{\partial e_{p h}}{\partial\left[V_{j}\right]_{h}^{u}} \cdot \frac{\partial\left[V_{j}\right]_{h}^{u}}{\partial V_{j}^{l}} \\
& \frac{\partial e_{p h}}{\partial V_{j}^{u}}=\frac{1}{2} \cdot \frac{\partial e_{p h}}{\partial\left[V_{j}\right]_{h}^{l}} \cdot \frac{\partial\left[V_{j}\right]_{h}^{l}}{\partial V_{j}^{u}}+\frac{1}{2} \cdot \frac{\partial e_{p h}}{\partial\left[V_{j}\right]_{h}^{u}} \cdot \frac{\partial\left[V_{j}\right]_{h}^{u}}{\partial V_{j}^{u}}
\end{aligned}
$$

By using the Eq. (24), we have:

$$
\begin{aligned}
& \frac{\partial e_{p h}}{\partial V_{j}^{l}}=\frac{1}{2} \cdot \frac{\partial e_{p h}}{\partial\left[V_{j}\right]_{h}^{l}}\left(1-\frac{h}{2}\right)+\frac{1}{2} \cdot \frac{\partial e_{p h}}{\partial\left[V_{j}\right]_{h}^{u}} \cdot \frac{h}{2} \\
& \frac{\partial e_{p h}}{\partial V_{j}^{u}}=\frac{1}{2} \cdot \frac{\partial e_{p h}}{\partial\left[V_{j}\right]_{h}^{l}} \cdot \frac{h}{2}+\frac{1}{2} \cdot \frac{\partial e_{p h}}{\partial\left[V_{j}\right]_{h}^{u}}\left(1-\frac{h}{2}\right)
\end{aligned}
$$

For more details regarding to derivatives of $\frac{\partial e_{p h}}{\partial\left[V_{j}\right]_{h}^{l}}$ and $\frac{\partial e_{p h}}{\partial\left[V_{j}\right]_{h}^{u}}$ terms and also similar calculations for parameters $W_{i j}, B_{j}, B$, a reader may refer to Ishibuchi et al. (1996). On the basis of obtained amounts for adjusting $\Delta V_{j}(t)$, the weights $V_{j}=\left(V_{j}^{l}, V_{j}^{c}, V_{j}^{u}\right)$ are obtained as follows:

$$
\begin{aligned}
& V_{j}^{l}(t+1)=V_{j}^{l}(t)+\Delta V_{j}^{l}(t) \\
& V_{j}^{u}(t+1)=V_{j}^{u}(t)+\Delta V_{j}^{u}(t) \\
& V_{j}^{c}(t+1)=\frac{V_{j}^{l}(t+1)+V_{j}^{u}(t+1)}{2}
\end{aligned}
$$

\section{Learning algorithm}

Step 1: For neural network parameters, weights and Bias of units, the first amount is considered.

Step 2: step3 is repeated for cut levels $h=h_{1}, h_{2}, \ldots, h_{n}$

Step 3: the following method is repeated for input data $P=1,2, \ldots, m$

- In the cut level " $h$ ", the output amounts of the neural network, $O_{p}$ is calculated for the analogous input vector $X_{p}$.

- Through using the cost function $e_{p h}$, the first amounts of the network's parameters are modified. 
Step 4: if the conditions of stopping algorithm are not satisfied on the basis of the number of repetition times or obtaining the maximum of the considered error, it is returned to stop one again.

For calculating customer satisfaction amount, just lower bound of fuzzy inference system's rules is activated and the satisfaction amount is displayed on basis of fuzzy number, customer feedback, and also fuzzy number is considered. Then the overall satisfaction of customers is obtained through some fuzzy numbers. For expressing the whole satisfaction range of customer or customers, defuzzification methods such as Center of Gravity (COG), or Mean of Maximum (MOM) is used. If the customer's judgments are received through quantities amounts, calculating the whole satisfaction is performed according to Mamdani fuzzy controller. For each input vector, some rules are activated and the final output is calculated through de-fuzzification methods.

\section{Case study}

The case setting which is practical has been designed to test the practical validity of the theoretical construction. In other words, it shows how relevant and fruitful it is for managers in a particular situation where they need to find out how to develop their approach for measuring customer satisfaction. The chosen case organizations delivered large automation and information systems for external customers. The location of case organization was located in the South part of Iran and had a staff of 25000, approximately. It was a global market and technology leader in the development of realtime supervisory control and data acquisitions systems for the Aluminum industry. Case organization was managed almost independently due to the fact that it was the parent corporation operated mainly in the paper industry. Management in this case organizations considered customer satisfaction to be an important factor to be considered, but they also recognized that there had been some serious problems related to implementing customer satisfaction surveys.

The research method was based on intense involvement with case organizations and data collection was based on interviews and observations. To do so, a questionnaire was designed which consists of 53 questions about financial, welfare and hygienic facilitates, occupational improvement, strategies and management policies, the human relations quality was observed in the working place, occupational security and social base of the profession, so that the responses of these 30 questions were verbal and shown by very satisfied, relatively satisfied, a little satisfied and not satisfied terms. They included observations, the analysis of archives such as customer surveys and action plans were created on the basis of survey results, and interviews. Also, a questionnaire on basic cultural assumptions was sent prior to interviews to facilitate and structure discussion during the interviews.

Meanwhile, through the aforementioned method (CSM\&FNN) the satisfaction range of workers and employees were calculated. In doing so, the customer satisfaction measurement method was planned through using fuzzy neural network with the $\mathrm{C}++$ programming language. In Fig. 5, the structure of CSM\&FNN for measuring customer satisfaction and the effective features on relationship between customers are demonstrated in Table 1.

\section{Table 1}

Characteristics of data sets considered

\begin{tabular}{ccc}
\hline Name & Value Type & Domain \\
\hline Age & Linguistic & Very Young, Young, Middle, not old, old \\
Gender & Nominal & Male, Female \\
Education & Linguistic & under diploma, diploma, technician, BS, MS , PHD \\
Q1-Q53 & Linguistic & very satisfied, relatively satisfied, little satisfied and not satisfied \\
Feedback & Linguistic & very satisfied, relatively satisfied, little satisfied and not satisfied \\
\hline
\end{tabular}

In this case, several types of customer surveys existed. They were not officially part of the quality management system of the organization, each department had its own survey process, and the analysis 
of information was not performed effectively on a cross-organizational level. Interviews, survey results and stated objectives of the organization indicated that the organization was customer oriented, and had a strong belief that the customer dominates the supplier and that the mission of the organization was to contribute to the success its customers. However, the personnel at the organization believe that it, as a technology leader, they were in the position of anticipating and even creating customer's needs, which decreases the validity of the customer satisfaction survey data. There were serious concerns with the objectivity and reliability of the information regarding customer satisfaction.

Initially, customer satisfaction surveys had an important role in the compensation system, but the focus on performance measurement had later shifted to financial measures, because customer satisfaction data were not perceived very reliable. There were also concerns about the validity of the information when it was removed from a customer or project specific context. On the other hand, several project managers expressed concerns that it was not very useful for project management either, because the information was usually received too late for any action to be taken in the project. At the end, the accomplished calculations have been mentioned and the output of model has been obtained in Fig. 5 .

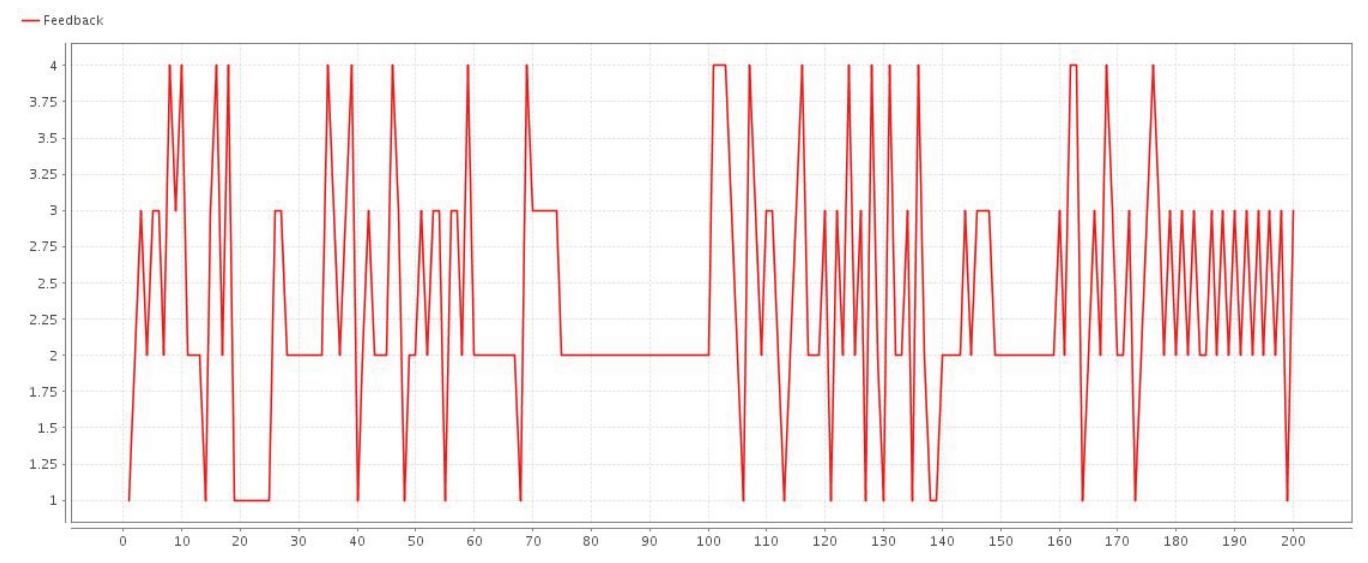

Fig. 5. Customer satisfaction fluctuation

\section{Conclusions}

Through comparing between presented models by Park and Han (2004), Zarandi et al. (2004), Itagaki et al. (1994), by applying the proposed approach in this research, we have concluded that customer satisfaction measurement using fuzzy neural network has maintained some beneficial features over those previously proposed approaches which did not consider any facts and figures, such as "receiving the customer's comments through both qualitative, quantitative ways", "supposition of linear relationship between satisfaction calculation functions" and determining the parameters of the membership grade function on the basis of received data from the customers". In the CSM\&FNN method, firstly the qualitative statements of satisfaction levels are expressed through fuzzy numbers according to feedback and comments made by the customer and, then the customer measurement overall satisfaction is calculated through using a fuzzy neural network model. The proposed approach has also been used for determining the result of knowledge based rules resulting from fuzzy inference system related to satisfaction amount. The fuzzy amounts of the overall satisfaction of customers were expressed using de-fuzzification methods through crisp numbers. Determining the membership grade functions of qualitative statements is one of the future potential research topics for improving this novel approach proposed in this paper, on the basis of data obtained from customer's comments. Another future work can be conducted on applying this system in multi project control system.

\section{Acknowledgement}

The authors would like to thank the anonymous referees for constructive comments on earlier version of this paper. 


\section{References}

Albayrak, T., \& Caber, M. (2016). Destination attribute effects on rock climbing tourist satisfaction: an Asymmetric Impact-Performance Analysis. Tourism Geographies, 18(3), 280-296.

Aleem, S., Capretz, L. F., \& Ahmed, F. (2016). Empirical investigation of key business factors for digital game performance. Entertainment Computing, 13, 25-36.

Austen, V., Herbst, U., \& Bertels, V. (2012). When 3+ 3 does not equal 5+ 1- New insights into the measurement of industrial customer satisfaction. Industrial Marketing Management, 41(6), 973-983.

Bayraktar, E., Tatoglu, E., Turkyilmaz, A., Delen, D., \& Zaim, S. (2012). Measuring the efficiency of customer satisfaction and loyalty for mobile phone brands with DEA. Expert Systems with Applications, 39(1), 99-106.

Choi, K. S., Cho, W. H., Lee, S., Lee, H., \& Kim, C. (2004). The relationships among quality, value, satisfaction and behavioral intention in health care provider choice: A South Korean study. Journal of Business Research, 57(8), 913-921.

Chou, J. S., Kim, C., Kuo, Y. C., \& Ou, N. C. (2011). Deploying effective service strategy in the operations stage of high-speed rail. Transportation Research Part E: Logistics and Transportation Review, 47(4), 507-519.

Grigoroudis, E., \& Siskos, Y. (2002). Preference disaggregation for measuring and analysing customer satisfaction: The MUSA method. European Journal of Operational Research, 143(1), 148-170.

Han, S. H., Yun, M. H., Kim, K. J., \& Kwahk, J. (2000). Evaluation of product usability: development and validation of usability dimensions and design elements based on empirical models. International Journal of Industrial Ergonomics, 26(4), 477-488.

He, F., Shen, W. X., Song, Q., Kapoor, A., Honnery, D., \& Dayawansa, D. (2015). Self-organising map based classification of LiFePO4 cells for battery pack in EVs. International Journal of Vehicle Design, 69(1-4), 151-167.

Höppner, F. (1999). Fuzzy cluster analysis: methods for classification, data analysis and image recognition. John Wiley \& Sons.

Hussain, R., Al Nasser, A., \& Hussain, Y. K. (2015). Service quality and customer satisfaction of a UAE-based airline: An empirical investigation. Journal of Air Transport Management, 42, 167-175.

Ishibuchi, H., Fujioka, R., \& Tanaka, H. (1992, March). An architecture of neural networks for input vectors of fuzzy numbers. In Fuzzy Systems, 1992. IEEE International Conference on (pp. 12931300). IEEE.

Ishibuchi, H., Kwon, K., \& Tanaka, H. (1995). A learning algorithm of fuzzy neural networks with triangular fuzzy weights. Fuzzy sets and systems, 71(3), 277-293.

Itagaki, A., Takashima, M., Ashino, Y., Nishio, C., \& Nakanishi, S. (1994, November). Fuzzy inference systems by genetic algorithm and factor analysis modeling for multivariate complex systems. In Emerging Technologies and Factory Automation, 1994. ETFA'94. IEEE Symposium on (pp. 199205). IEEE.

Kuo, R. J., Huang, M. H., Cheng, W. C., Lin, C. C., \& Wu, Y. H. (2015). Application of a two-stage fuzzy neural network to a prostate cancer prognosis system. Artificial intelligence in medicine, 63(2), $119-133$

Li, L. (2011). Assessing the relational benefits of logistics services perceived by manufacturers in supply chain. International Journal of Production Economics, 132(1), 58-67.

Li, Z., Kecman, V., \& Ichikawa, A. (2002). Fuzzified neural network based on fuzzy number operations. Fuzzy sets and systems, 130(3), 291-304.

Lin, W. B. (2007). An empirical of service quality model from the viewpoint of management. Expert systems with applications, 32(2), 364-375.

Nagamachi, M. (Ed.). (2016). Kansei/affective engineering. CRC Press.

Pan, Y., Sheng, S., \& Xie, F. T. (2012). Antecedents of customer loyalty: An empirical synthesis and reexamination. Journal of Retailing and Consumer Services, 19(1), 150-158. 
Park, J., \& Han, S. H. (2004). A fuzzy rule-based approach to modeling affective user satisfaction towards office chair design. International Journal of Industrial Ergonomics, 34(1), 31-47.

Saeidi, S. P., Sofian, S., Saeidi, P., Saeidi, S. P., \& Saaeidi, S. A. (2015). How does corporate social responsibility contribute to firm financial performance? The mediating role of competitive advantage, reputation, and customer satisfaction. Journal of Business Research, 68(2), 341-350.

Zadeh, L. A. (2011). A note on Z-numbers. Information Sciences, 181(14), 2923-2932.

Zarandi, M. H. F., Turksen, I. B., \& Maadani, B. (2004, June). Customer satisfaction assessment with fuzzy queries and ANFIS for an automotive industry. In Fuzzy Information, 2004. Processing NAFIPS'04. IEEE Annual Meeting of the (Vol. 2, pp. 723-728). IEEE.

Zeinalizadeh, N., Shojaie, A. A., \& Shariatmadari, M. (2015). Modeling and analysis of bank customer satisfaction using neural networks approach. International Journal of Bank Marketing, 33(6), 717732.

Zimmermann, H. J. (1996). Fuzzy Control. In Fuzzy Set Theory-and Its Applications (pp. 203-240). Springer Netherlands.

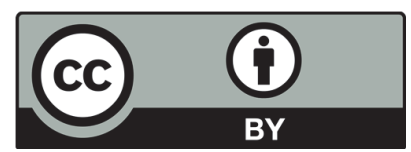

(C) 2016 by the authors; licensee Growing Science, Canada. This is an open access article distributed under the terms and conditions of the Creative Commons Attribution (CC-BY) license (http://creativecommons.org/licenses/by/4.0/). 